\title{
THE STANDARD OF HOME LIFE AND THE INFANT MORTALITY PROBLEM.
}

By Miss MARTON FITZGERALD,

Lady Samitary Inspector, Derby.

(ASSOCHATE.)

T must be the opinion of everybody engaged in work connceted with the 1 infantile mortality problem, that that problem is a very complex one and that its contributing factors are very far from being completely understoorl. However, while we wait for fuller light, we do know that feeding has a very considerable influence, and that the hand-fed child comes out badly in the struggle for existence. Moreorer, great and amazing is the ignoiance of women in the matter of child-rearing. Hence, an obrious duty devolving upon the community and resulting in the work undertaken by the municipalities in the direction of instructing the mothers; and while their appointed officers carry out this task, rast stores of information may be incidentally accumulated, which when tabulated should be the me:ms of contributing to much fuller knowledge on the subject.

There are several lines of investigation open to those engaged in the routine work of visiting homes after registration of births. Speaking generally, I should say that they are of a sociological rather than at purely scientific nature, and the method is one of obscrvation rather than research. I only offer details of one line of investigation which is directed towards calculating the death-rates of infants, and the incidence of the causes of deatl, accordin! to the classification of their homes; the condition of the home beingre regarded as an indes to the type or grade of the inhabitants. This classification will be hetter understood if I explain the circumstances which led to its aldoption in Derby.

In investigating deaths of infauts from summer diarroea it was oly- 
served how neavy was the incilence upon the better-clisss of home, and yet at the same time there were a considerable number of hand-fed or partially hand-fed infants in homes of varying clegrees of clirt and disorder, kept under constant supervision and visited frequently, chiefly on account of the slovenly incapacity of their mothers. Deaths from diarrhœa amungst these infants, who were obviously exposed to great danger, were by no means common.

Loroking up my predecessor's reports on diarrhon deaths in the summers of $1 ! 142$ and 1903 , I found her reports to be in angreement with my own, so that idiosyncracy of observation does not account for the preponderance of clean homes over dirty ones in this investigration.

Of a total of 151 diarrho:i deaths investigated in the summers of 1902 to 1905 inclusive, 108 uccurred in clean or very clean homes: 34 occurred in fairly clean homes; and only ! in dirty homes. The lifferent kincls of sanitary conveniences do not seem to have exercised an influence.

Mrs. Franks, the Chief Lady Sanitary Inspector for Sheffield, has very kindly supplied me with the results of similar investigations made in Sheffield which strikingly confirm my own. Mrs. Franks informs me that of a total of 778 deaths of infunts from diarrheen vecurring in Sheftield in 1901 not one occurrerl in the insanita:y Crofts area subsequently demolished. And of these 778, only 1015 occurred in dirty houses.

It seems clear that so far as the incilence of summer diarrhoa upon the different classes of houses is concerned, thit the unexpected liappe $\mathrm{ns}$; that there is something yet to be explained, and the question arises, what is the distribution of hand-fed and partially hand-fed infants into satisfactory and unsatisfactory homes? For this reason it was decided at the heginning of this present year to adopt a classification of the homes in reporting upon visits made after the registration of births. The cardindex system makes it possihle to keep several clistinct lines of investigation going at one time, and to compile the results with a minimum of trouble. Extracting information of this kind, involving very large numbers, from an ordinary register is a long and tedious task.

Each infant has a card to itself recording its name, address, date of birth and condition, and, should it die, its death. The mode of feeding is indicated by the colour of the card : there is a range of six colours. Such facts as whether the infant is a first-born child or not; if its mother goes out to work, either regularly to a factory or occasionally to do a day's washing or cliaring, are noted. In addition to this information, a mark is put upon each card denoting the class of home. We have adopted the very simple clevice of cutting off the corners to indicate the class, such a 
method rendering sorting and compiling very easy. The division is into three classes. In the first, the habits of the people are degraded, cleanliness and decency are lacking, and the houses are structurally defective, dirty, ill-ventilater or overcrowded. In the second, the conditions are still unsatisfactory, although not to so great a degrec; and houses structurally capable of being made into decent homes are debased by the negligence and incapacity of the women. This class occupies a middleway between sheer degradation and the minimum of a decent standard of living. The influence of alcohol is certainly implicated in the first class and most probably in the second also, but it is not easy to estimate its extent. The third class exlibits signs of groot housewifery, cleanliness and love of order; the dwellings are structurally satisfactory or are made the best of by the ingenuity, industry and perseverance of the tenant. All above this minimum are included in class 3. If a further class were made it could only be based on a greater margin of confort, which is departing somewhat from the original plan.

It is obvious that a classification of this kind presents some difficulties. The divisions must be fairly broad, for matters pertaining to human life are very difficult to pigeon-hole. At the same time they must be definite enough to admit of agreement on the part of different workers. The classification is the result of a personal estimate of each home. It does not depend primarily upon locality, size of house, occupation of the husband, or family income, so much as upon evidence of habits of sobriety and industry, and the judicious use of the money earned. It las this advantage, that being based upon observation, it can be pursued without categorical questioning, a mode of procedure to be avoided as far as possible. For investigations in infant mortality, I think this method las a sounder hasis than one having reference to the poverty line. It implies loth considerations of hygiene and of character. What is songht is some index to the grades of the people, and from that lasis to calculate the infant deatli-rate in each grade, and in addition, the incidence of the causes of death according to each grade. A good deal has heen said alout diarrhœa, lut that is merely on account of the apparent anomaly in that direction having suggested the idea of a clissification. There are those other causes which bulk so largely in the infant mortality rate, debility and prematurity. It would be interesting to know in which of these strata of human society are born those children whose lives flicker out within a few days of lirth.

It is not claimed that the scheme has yet passed heyond the experimental stage. Probaluly it will have to be suljjected to modification or 
enlargement. But I think the reasons set forth for undertaking it indicate that in this direction there is a field for profitable observation, although it will he merely supplementary to the more purely scientific lines of investigation.

Sir Charces Cameron (Dublin) said that the paper was most interesting. He would ask Miss Fitzgerald a question. She said that of 151 cases of infantile diarrhœa, 108 occurred in clean or very clenn houses, $3+$ in fairly clean, and 9 in dirty houses. This would appear to shew that the cleaner the house the more likely diarrhoa to occur in it. 'Lhis paradox perhaps might be explained by there being a very small percentage of the total houses in the dirty class. It would be desirable for the Registrar General of England to do as the Registrar General of Irelaud did : give the occupations of the decedents. In Dublin there was an extremely small infantile mortality amongst the groups of the independent classes and the professional classes, while amongst the general service classes and labourers the mortality was more than 200 deaths per 1000 birtlis. As regards hand-fed children, he might reply that ladies now chiefly nursed their infants vicariously, which proved that when hand feeding was properly conducted it was by no means so bad as it was believed to be. He had seren children who werc all hand-fed. and were stont, hearty, and fat.

Dr. J. MI. Fontescere-Brickdate (Bristol) said he should like to know how far the following factors could be consiclered as contributing to the fact reported by Miss Fitzgerald : (1) incidence of artificial feeding in both classes, especially with regard to patent foods; (2) occurrence of predisposing marasmus; (3) senson of birth, as affecting age of child when exposed to zymotic enteritis. His experience at the out-pitient department of the Children's Hospital made bim think marasmus and hand feeding very common among woll-tr-do artizans.

Dr. W. H. Sxyoss (Bath) said since the introduction of the Midwives Act every inspector under the Act had had it in his power to get information of births within twenty-four hours without fee and without injustice. In Bath they supplied the midwives with cards bearing all the particulars required by rules of the Central Midwives Board, and they were asked to fill in those particulars (except as regards the condition at end of ten days) and send in the stamped addressed envelopes as som as possible. The sub-registrars were also supplied with cards, and he got is daily return of deaths and births from them, the cards buing the official copy of certificates. Cards should be of different colour for different districts rather than for different diseases, as then they are filed out automatically in districts. An inquiry should be held concerning the deatlis of 


\section{Standard of Home Life and the Infunt Mortatity Problem.}

all children under one year of age: persons could generally be madr ashamed of an infant dying.

Dr. D. S. Davies (Bristol) said a spealiel sugrested that the explanation wis possibly in part that the very poor were more motherly, i.e., devoted more intimate attention to their infants than those in a somewhat better position. The iuportance of the work that could be, and hal been, done by the employment of lady inspectors in many towns was emphasised, and the speaker regretted that Bristol had not yet scen its way to appoint them ; but stated that public opinion was changing, and there was a possil,ility of obtaining their valuable assistance in the near future in the class of work for which they were especially suitable, supervision of female labour in factories, of feerling of infants, etc.

Mrs. Gertrulue Fraxis (Sheffield) said she endorsed what Miss Fitzgerald had said in her paper $r e$ the deaths from summer diarrhoca in Sheffield during 1901. Out of 7 s 8 deaths risited, 643 occurred under one year of age. 16: were first children, and only 106 occurred in dirty houses. The industries of sheffield being heavy do not lend themselves to women labour, because only 62 of these children were put out to nurse. She must say that a larger proportion of the children in the better homes were hand-fed, but as reasonable precautions were taken in these homes, it should in some meisure counteract the disadvantage of hand feeding. Her experience as inspector of midwives had led her to the belief that many of the children were tampered with both before and also at the time of their birth. 'This reduced their vitality and made them more susceptible to anything that presented iteelf.

Dr. S. G. Moone (Huddersfield) pointed out that the general practitioner might at least in one direction help preventive medicine very usefully. He might realise that the newly born infant is very susceptible to adverse influences, and he might dispel some of the ignomance which at present exists among mothers. When the spealier first examined infant mortality systematically some years ago, he considered it worth while to find out the mortality among newly bom lower animals, for the purpose of comparing this with the human rate. Though among animals of considerable commercial value, the mortality of the newly born is very small, e.g., very few pedigree racehorse foals die, still the deaths are commonly very numerous among the newly born lower animals, pointing to the fact that all very young living things are very susceptible to adverse external influences. It would therefore be a good thing if the practitioner would, as well as seeing that the mother had recovered from the confinement, extend his attention to the infant, and attempt to secure for it a good start in life.

Miss Firzginald (Derby) said, in reply, that the apparent anomaly was completely accounted for by the greater number of hand-fed children in the 
better class of home. It was pointed out that the question was practically concerned with hand-fed children only, and that the olject of sereling to ascertain the distribution of lıand-fed or partially hand-fed childiren into satisfactory and unsatisfactory homes was to ascertain if the incidence of epidemic diarrhu:a was acturll!! and not apparently higher in the better class of lome, and whether the slum child did manifest a higher degree of resistance to this particular disease than the more delicately nurtured child. If the slum children were numerically less, their points of exposure to danger in this particulal respect were ten times greater; the mother's of the lowest class bought milk of worse quality, stored it more imperfectly, and more frequently mixed it with chenp pernicious patent foods than did the mothers of the more respectable class. In reply to Dr. Moore, she said that rast stores of information as to the causes of drath did of cuurs' exist in every Public Health Department, but she believed that no attempt liad yet been made to classify infant morrality on a sociological basis. 'Thr object of such a classification of infant lifi. was to cletermine the death-rate in each grade and the incillence of the causes of death (supposing any marked difference to emerge) according to each grade. 